\title{
Shell-sheddable/Core-degradable ABA Triblock Copolymer Nanoassemblies: Synthesis via RAFT and Concurrent ATRP/RAFT Polymerization and Drug Delivery Application
}

Arman Moini Jazani, ${ }^{\#}$ Newsha Arezi, ${ }^{\#}$ Chaitra Shetty, Jung Kwon Oh*

Department of Chemistry and Biochemistry, Concordia University, Montreal, Quebec, Canada H4B 1R6

E-mail: john.oh@concordia.ca 
Figure S1. ${ }^{1} \mathrm{H}-\mathrm{NMR}$ spectrum of $\mathrm{A} 3$ in $\mathrm{CDCl}_{3}$.

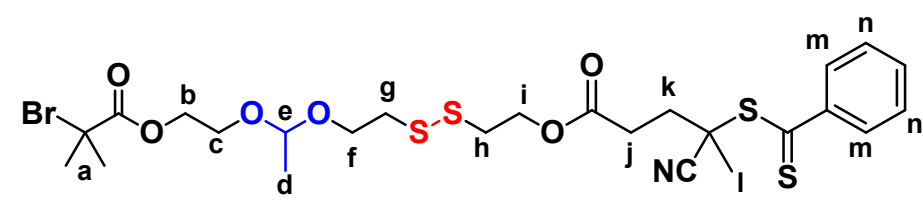

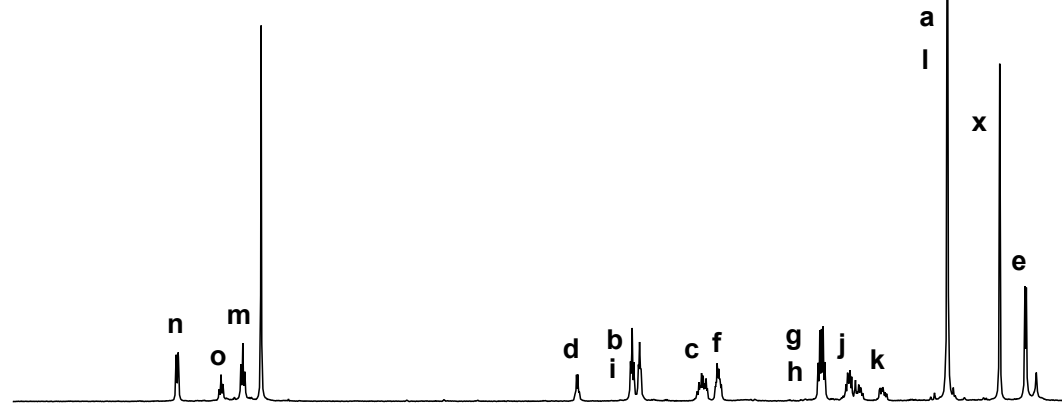

$\begin{array}{lllllllllllllllllllllllll}9.0 & 8.5 & 8.0 & 7.5 & 7.0 & 6.5 & 6.0 & 5.5 & 5.0 & 4.5 & 4.0 & 3.5 & 3.0 & 2.5 & 2.0 & 1.5 & 1.0 & 0.5 & 0.0 & -0.5 & \end{array}$

Figure S2. ${ }^{13} \mathrm{C}-\mathrm{NMR}$ spectrum of $\mathrm{A} 3$ in $\mathrm{CDCl}_{3}$.

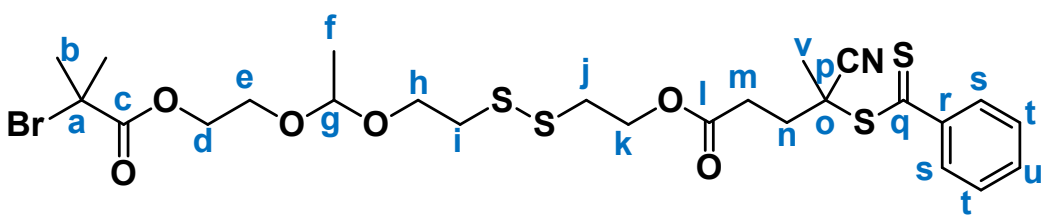

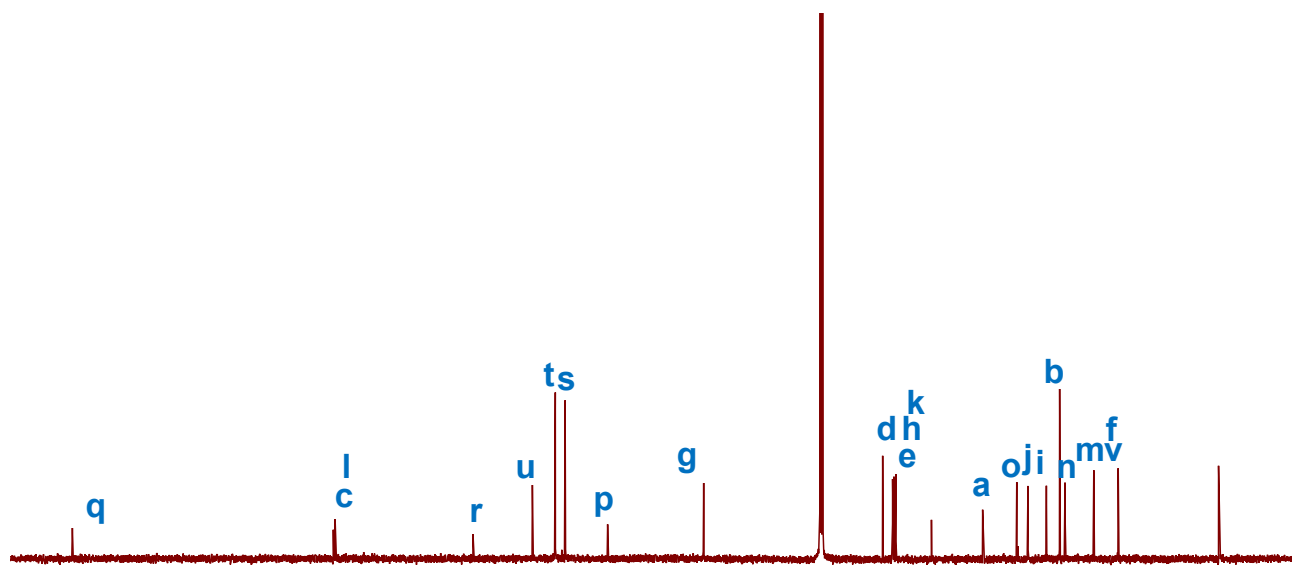

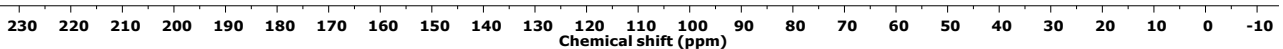


Figure S3. COSY NMR of A3 in $\mathrm{CDCl}_{3}$.

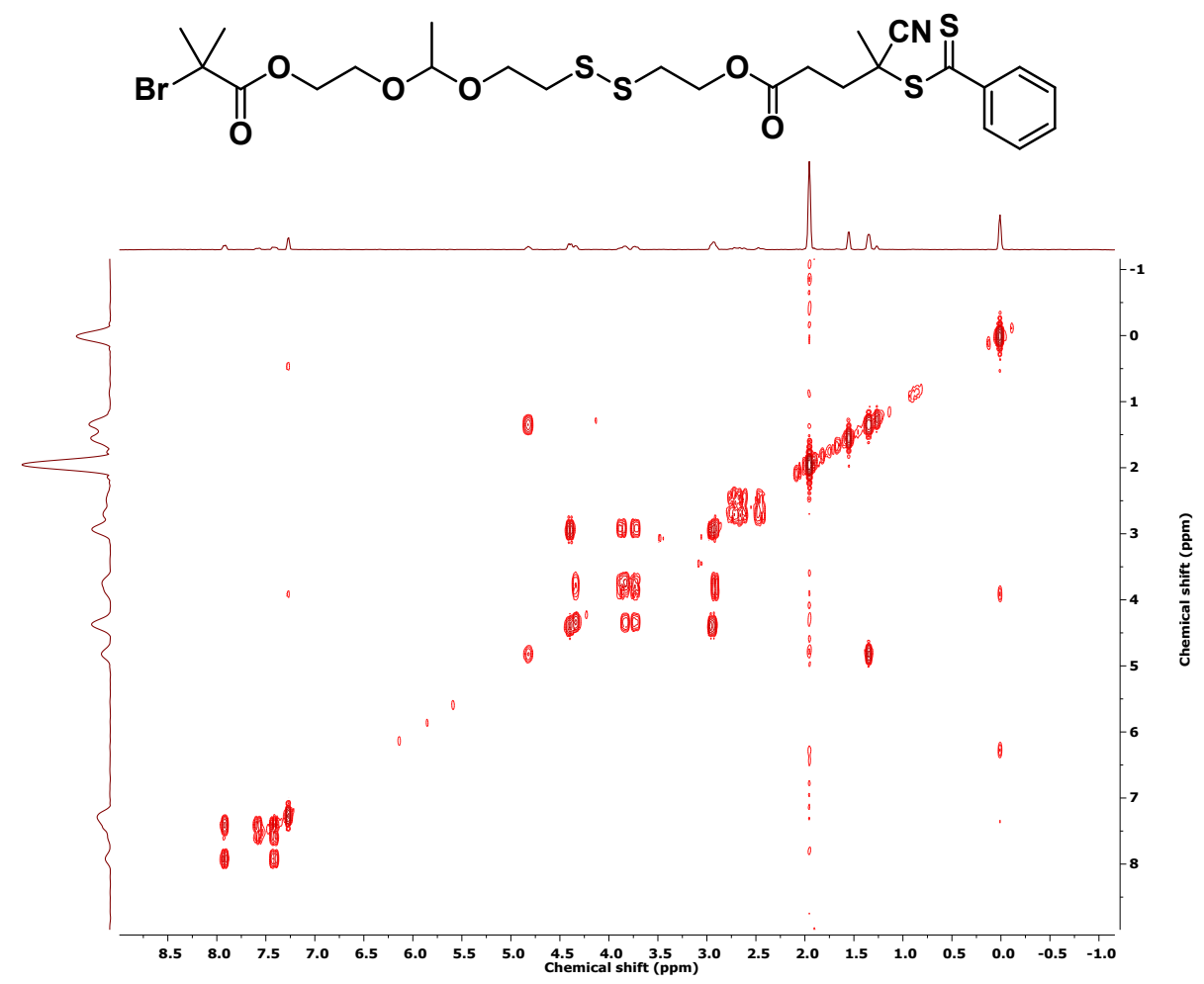


Figure S4. First-order kinetic plot over time (a), evolution of molecular weight and molecular weight distribution over conversion (b), and evolution of GPC traces for RAFT polymerization of OEOMA in the presence of A3. The straight lines in (b) are theoretically calculated $\mathrm{M}_{\mathrm{n}}$ values at conversion. Conditions for RAFT: $[\mathrm{OEOMA}]_{\mathrm{o}} /[\mathrm{A} 3]_{\mathrm{o}} /[\mathrm{AMBN}]_{\mathrm{o}}=30 / 1 / 0.2$ in anisole at $70{ }^{\circ} \mathrm{C}$. OEOMA/anisole $=0.6 \mathrm{wt} / \mathrm{wt}$.
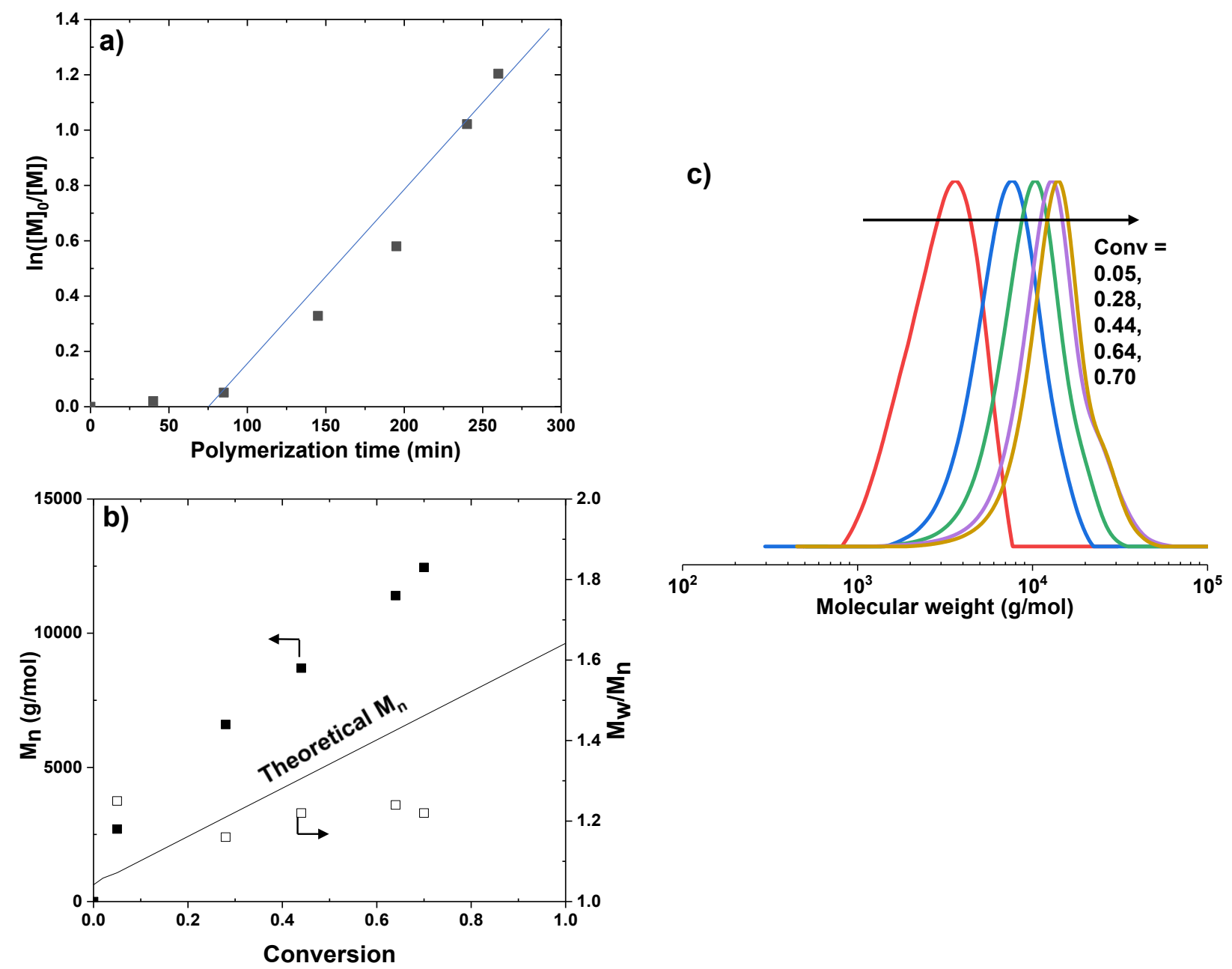
Figure S5. ${ }^{1} \mathrm{H}-\mathrm{NMR}$ of $\mathrm{P} 1$ precursor in $\mathrm{CDCl}_{3}$.
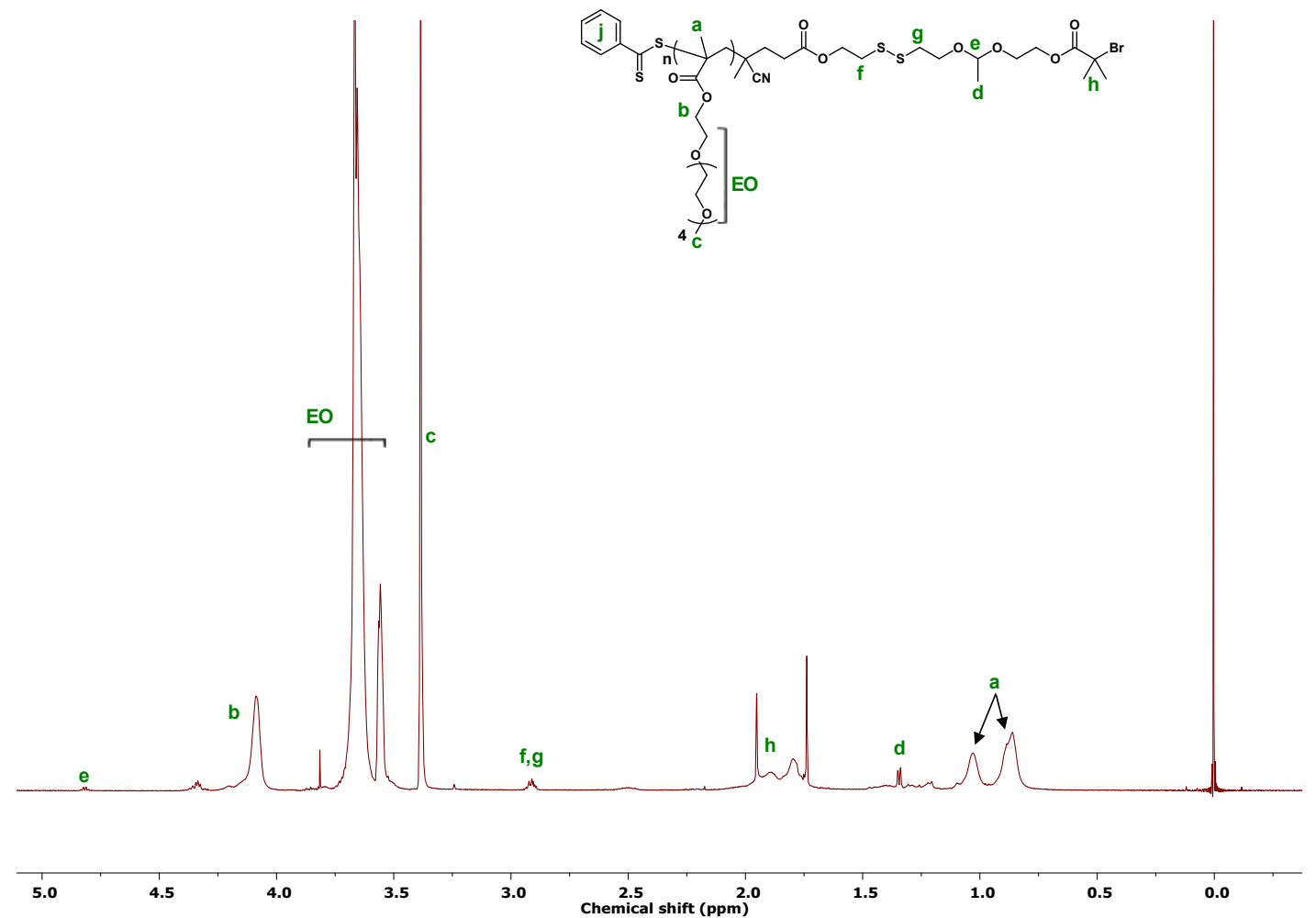

Figure S6. GPC diagrams of P2-40, P2-65 and P2-85 compared with P1.

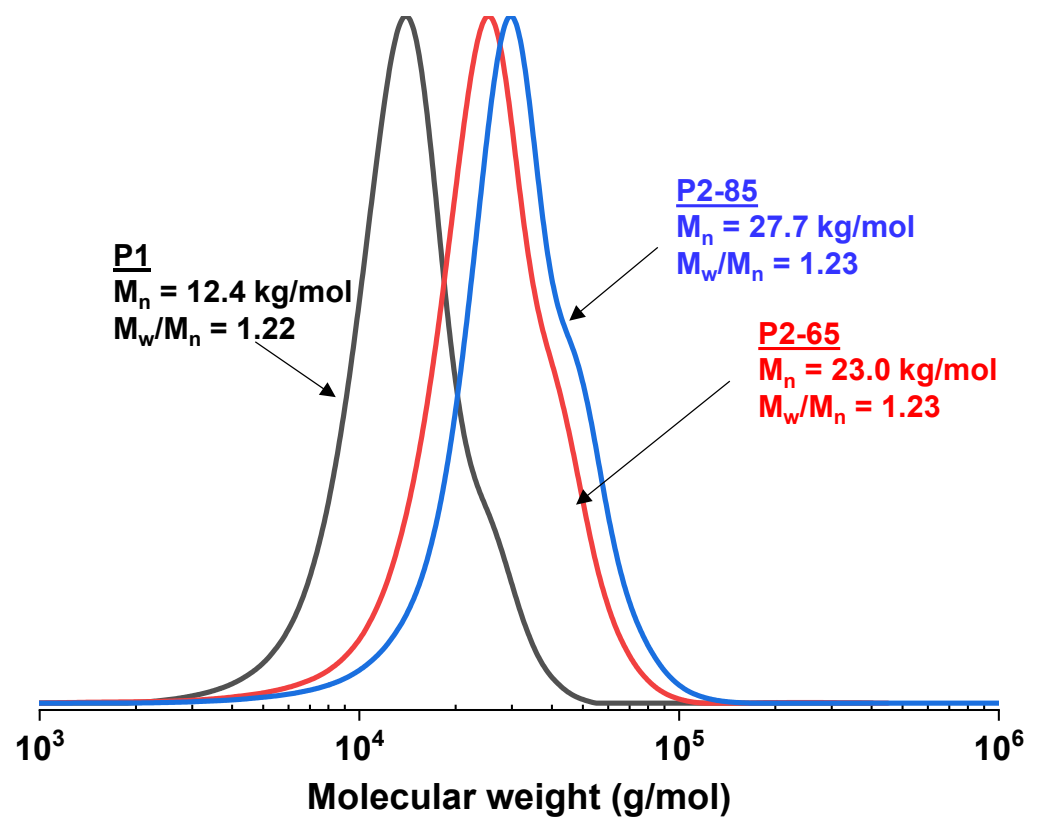


Figure S7. First-order kinetic plot over time (a), evolution of molecular weight and molecular weight distribution over conversion (b), and evolution of GPC traces for ATRP of HMssEt in the presence of $\mathrm{P} 1$ macro-RAFT agent, with $[\mathrm{HMssEt}]_{\mathrm{o}} /[\mathrm{P} 1]_{\mathrm{o}}=85 / 1$ (c) and 65/1 (d). The straight lines in (b) are theoretically calculated $\mathrm{M}_{\mathrm{n}}$ values at conversion. Conditions for ATRP:

$[\mathrm{P} 1]_{\mathrm{o}} /\left[\mathrm{Cu}(\mathrm{II}) \mathrm{Br}_{2}\right]_{\mathrm{o}} /[\mathrm{TPMA}]_{\mathrm{o}} /\left[\mathrm{Sn}(\mathrm{II})(\mathrm{EH})_{2}\right]_{\mathrm{o}}=1 / 0.05 / 0.15 / 0.4$ in anisole at $40{ }^{\circ} \mathrm{C}$. HMssEt/anisole $=0.36 \mathrm{wt} / \mathrm{wt}$.
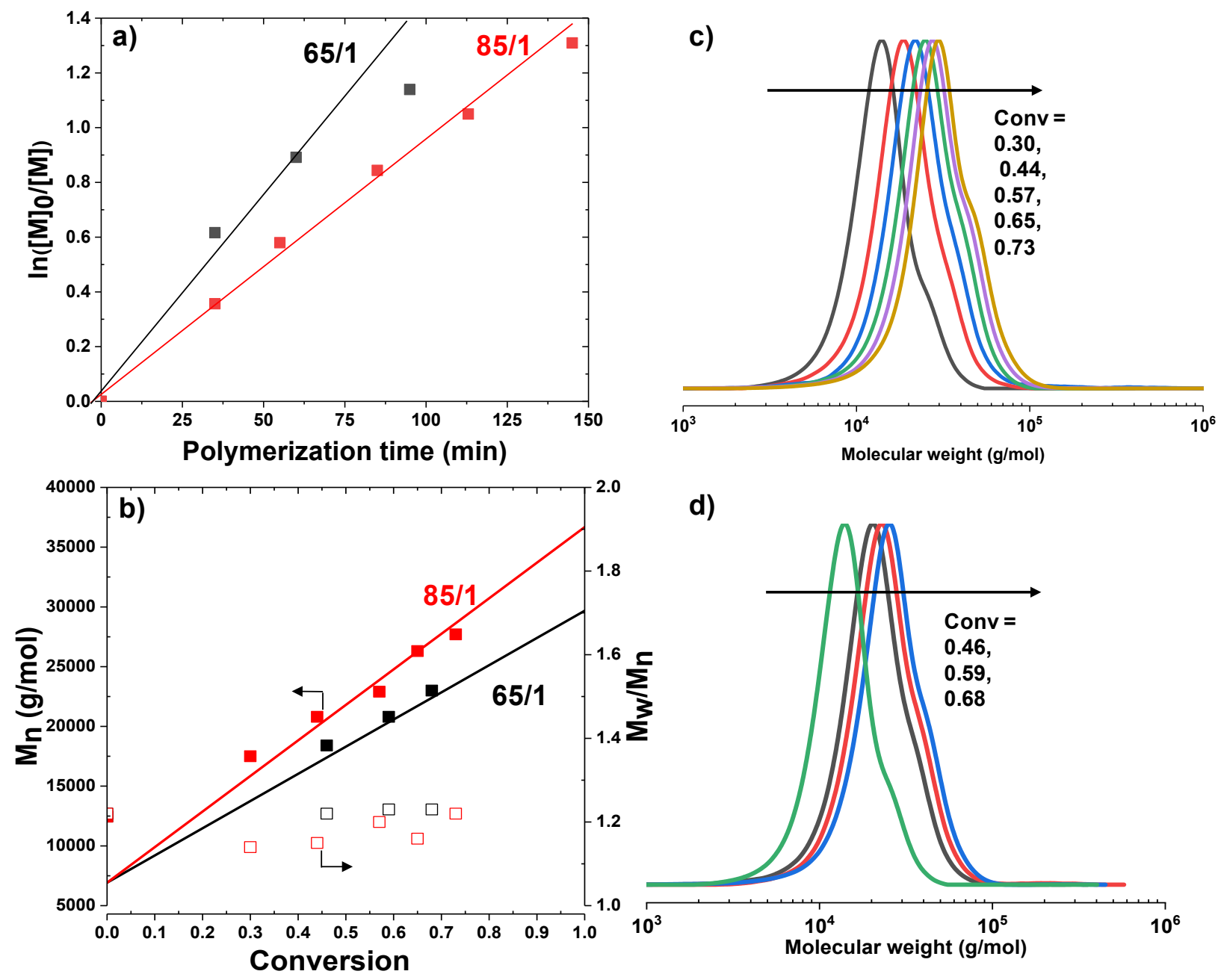

d)

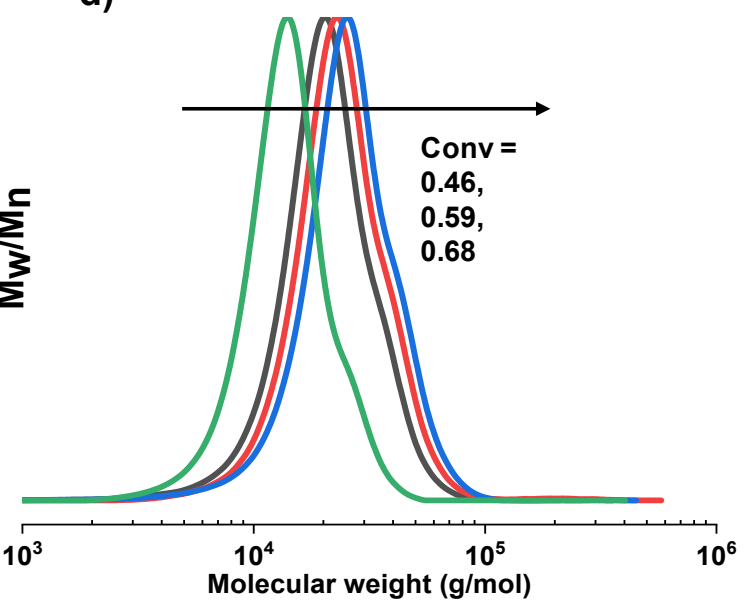


Figure S8. Overlaid fluorescence spectra (a), and maximum fluorescence intensity of NR over increasing amounts of P2-65 (b).
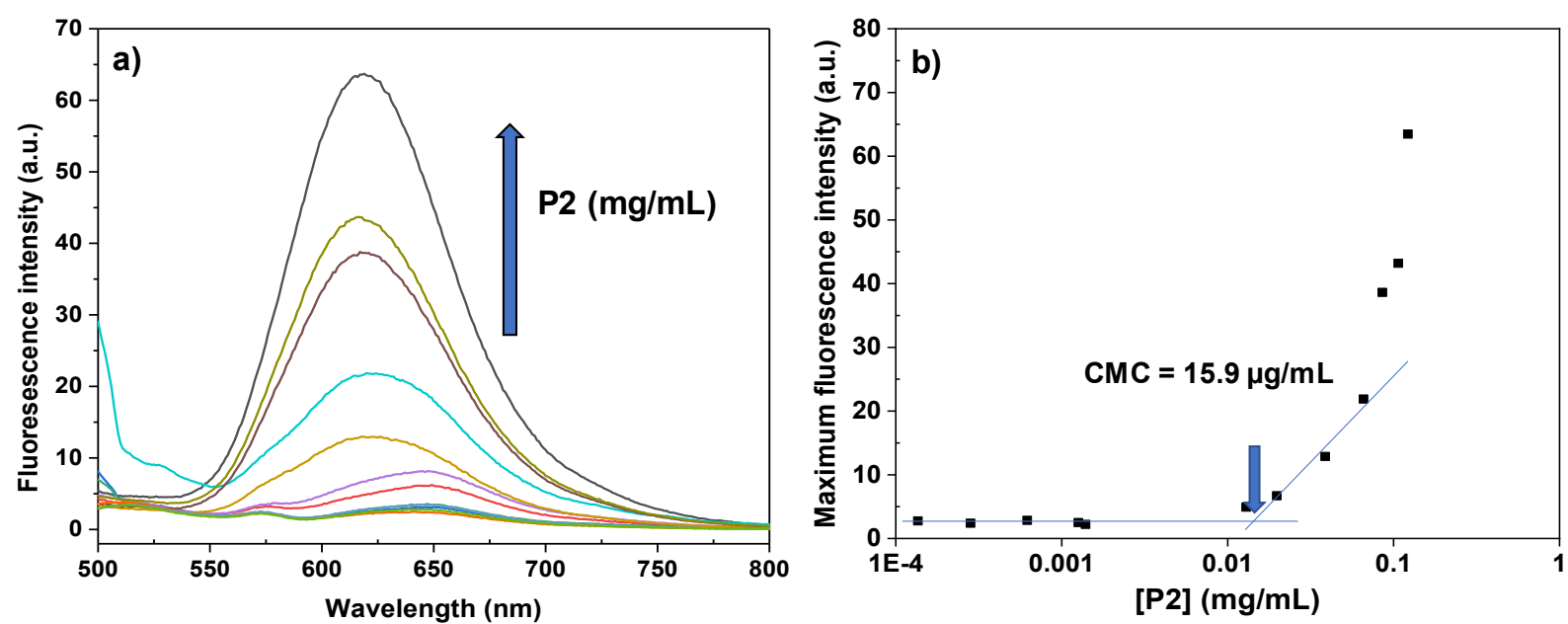

Figure S9. DLS diagram of aqueous NR-NPs of P2-65.

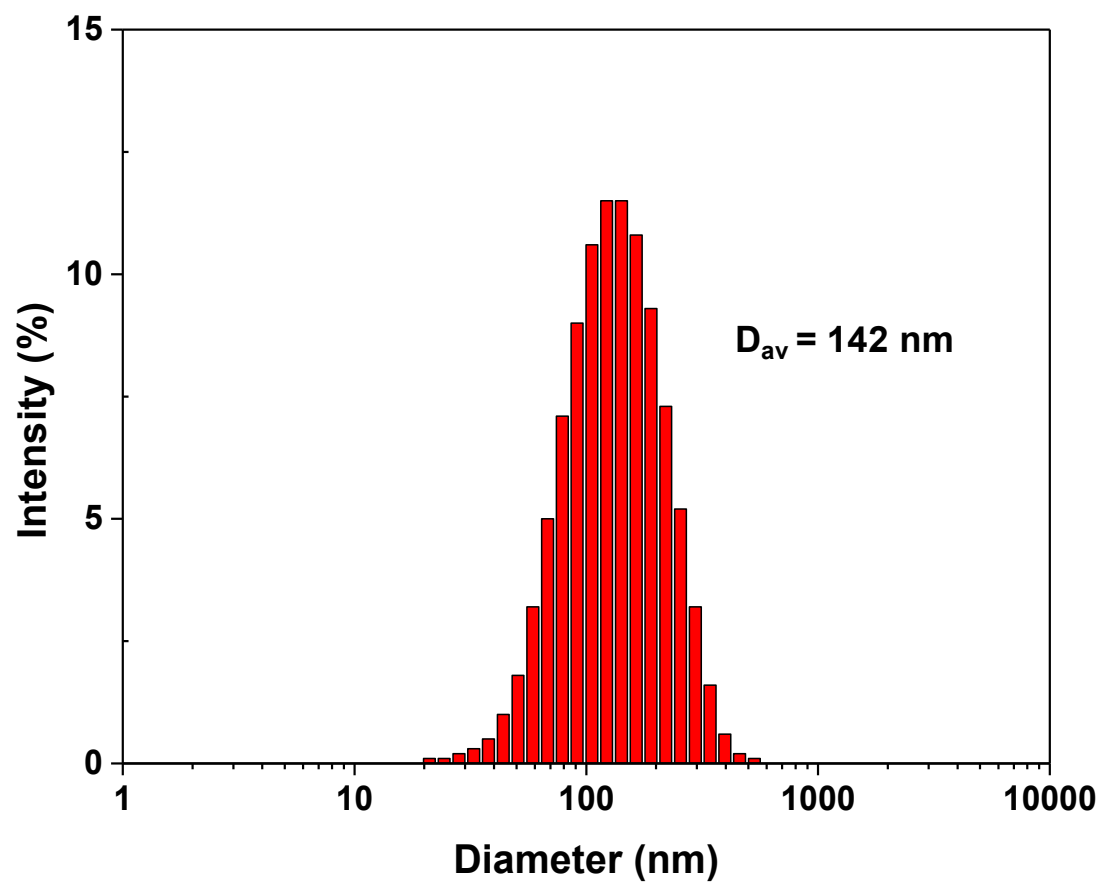


Figure S10. DLS diagrams and digital images of Dox-NPs of P2-65 before and after filtration using PES filter (average pore size $=400 \mu \mathrm{m}$ ).
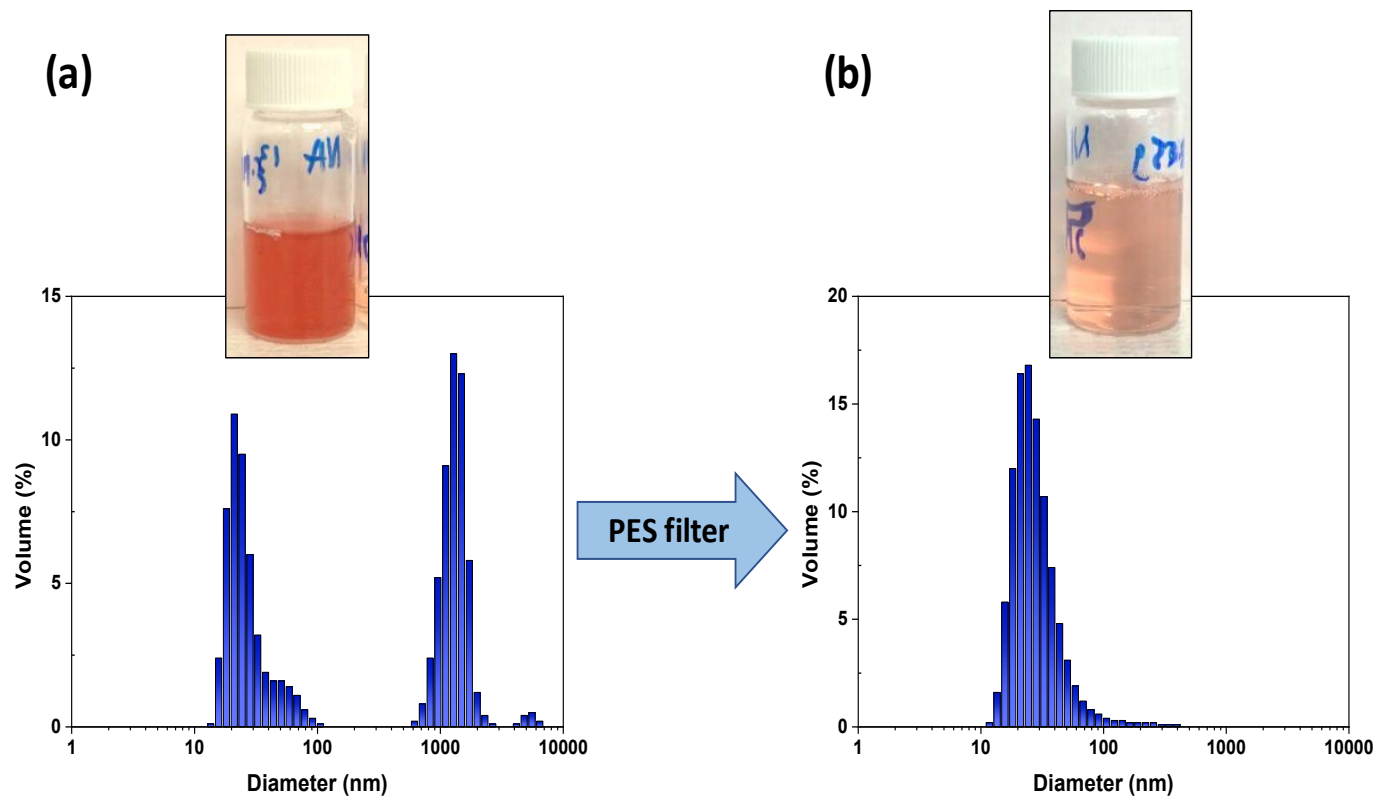

Figure S11. UV/Vis spectrum of a mixture of aqueous Dox-NPs $(1 \mathrm{~mL})$ with DMF $(5 \mathrm{~mL})$.

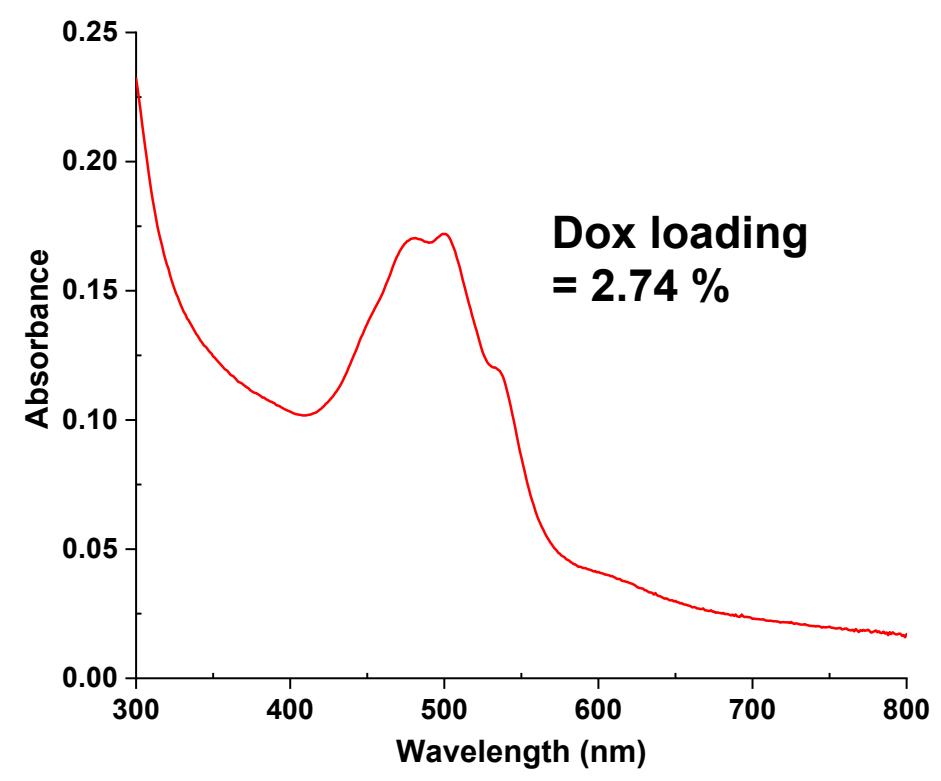

